\title{
Telmisartan Increases the Permeability of Endothelial Cells through Zonula Occludens-1
}

\author{
Chang Bian, ${ }^{a}$ Yihua $\mathrm{Wu}^{a}$, and Peng $\mathrm{CHeN}^{*}, a$ \\ ${ }^{a}$ Department of Cardiology, Second Affiliated Hospital, Zhejiang University School of Medicine; Hangzhou 310009 , P. R. \\ China. Received October 5, 2008; accepted November 28, 2008; published online December 24, 2008
}

\begin{abstract}
Angiotensin receptor-1 blockers (ARBs) have been used for the treatment of atherosclerosis. Tight junctions are very important in the regulation of cellular permeability which may have a profound role in atherosclerosis. The relationship between them is unresolved. The expression and distribution of zonula occludens-1 (ZO-1), the permeability of cultured endothelial cells, and the activity of phosphatidylinositol 3-kinase (PI3K) were all detected with various methods after cultured endothelial cells were exposed to valsartan and the special ARB telmisartan or combined with PI3K inhibitor wortmannin or the peroxisome proliferator-activated receptor gamma antagonist GW9662. We found that telmisartan but not valsartan downregulated ZO-1 mRNA and protein levels, disrupted the distribution of $\mathrm{ZO}-1$ in cultured endothelial cells, and increased the permeability of endothelial cells in a dose-dependent manner. When the PI3K inhibitor wortmannin was used, the effect induced by telmisartan was at least partly reversed. The role of the PI3K signaling pathway was further confirmed in the PI3K activity assay. GW9662 significantly blocked telmisartan-induced ZO-1 changes. Our results suggest that telmisartan disrupts the continuous pericellular distribution of ZO-1, downregulates the expression of ZO-1 in endothelial cells, and increases the permeability of endothelial cells at least partly through PI3K and the peroxisome proliferator-activated receptor gamma-dependent pathway.
\end{abstract}

Key words endothelial cell; telmisartan; zonula occludens-1; phosphatidylinositol 3-kinase; peroxisome proliferator-activated receptor gamma

The blockade of angiotensin II signaling appears to be a useful strategy for the treatment of atherosclerosis. Angiotensin receptor-1 blockers (ARBs) have been used to treat atherosclerosis in both animal models and humans. ${ }^{1,2)} \mathrm{Re}-$ cently, it has been found that the ARB telmisartan has an interesting structural resemblance to the insulin sensitizer pioglitazone, a thiazolidinedione ligand of the peroxisome proliferator-activated receptor gamma $(\operatorname{PPAR} \gamma)$ which has significant roles in atherosclerosis. ${ }^{3,4)}$ Whether telmisartan could be used to treat atherosclerosis with these two roles is unknown.

Increased permeability of the endothelium is thought to be crucial in atherosclerosis because it allows circulating lipoproteins and inflammatory cells to infiltrate into the intima which is a necessary step in atherosclerosis. Barrier function is maintained by tight junctions and adheres protein complexes between adjacent endothelial cells. ${ }^{5)}$ Zonula occludens-1 (ZO-1) is critical in forming and stabilizing tight junctions by binding occludin to cytoarchitecture, ${ }^{6}$ and plays an important role in regulating cellular permeability. ${ }^{7)}$

We sought to determine whether telmisartan could affect the expression and localization of ZO-1 in endothelial cells. In the present study, we further investigated how telmisartan interacts with ZO-1, with ARBs or PPAR $\gamma$. The involvement of the phosphatidylinositol 3-kinase (PI3K) signaling pathway was also examined.

\section{MATERIALS AND METHODS}

Culture and Treatment of Human Umbilical Vein Endothelial Cells (HUVECs) HUVECs were prepared as previously reported. ${ }^{8)}$ Cells were grown in Roswell Park Memorial Institution (RPMI)-1640 medium (Genom Biomed) with $20 \%$ fetal bovine serum (FBS) (Sijiqing Biological) at $37^{\circ} \mathrm{C}$ in a humidified atmosphere of $5 \% \mathrm{CO}_{2}$. Cells were replaced with serum-free medium until $90 \%$ confluence and used for experiments. Cultured HUVECs were treated with serum-free RPMI-1640 medium (control), $1 \times 10^{-4} \mathrm{M}$ valsartan (Novartis), $1 \times 10^{-6}-1 \times 10^{-5} \mathrm{M}$ telmisartan (HiSun Pharmaceutical), or combined with the PI3K inhibitor wortmannin $\left(1 \times 10^{-7} \mathrm{M}\right)$ (Sigma) for $24 \mathrm{~h}$. In a further test, HUVECs were exposed to the PPAR $\gamma$ antagonist GW9662 (5 $\mu \mathrm{g} / \mathrm{ml})$ for $24 \mathrm{~h}$.

Western Blot Analysis Aliquots of cell lysates were separated on $11 \%$ sodium dodecyle sulfate (SDS)-polyacrylamide gel and transferred to nitrocellulose membrane filters. The filters were blocked with Tris-buffered saline-Tween 20 (TBS-T) buffer containing 20\% skim milk and incubated with a mouse monoclonal antibody to human ZO-1 (1:400) (Zymed) for $2 \mathrm{~h}$ at room temperature, followed by the addition of goat anti-mouse immunoglobuline $\mathrm{G}(\operatorname{IgG})(\mathrm{H}+\mathrm{L}) /$ horse radish peroxidase (HRP) secondary antibody (1: 10000) (Pierce), and ECL (Pierce) visualization of the bands. All experiments analyzed by Western blotting were repeated three times. Expression was quantitated using Quantity-one software (Bio-Rad). $\beta$-Actin (Santa Cruz) was used as the input control.

Reverse Transcription-Polymerase Chain Reaction (RTPCR) RNA was purified using a Minikit (Qiagen) according to the manufacturer's instructions and dissolved in $20 \mu \mathrm{l}$ of DEPC-treated water. Total RNA of HUVECs was converted into cDNA with oligo dT15 by M-MuLV reverse transcriptases (Fermentas). RT-PCR was performed with the following primers: forward primer, 5'-AAAAGTGAACCACGAGATGCT-3'; and reverse primer, 5'-AAAGGTAAGGGACTGGAGATGA-3'. The reaction conditions for ZO-1 were $1 \times\left(94^{\circ} \mathrm{C}, 4 \mathrm{~min}\right), 30 \times\left(94^{\circ} \mathrm{C}, 30 \mathrm{~s} ; 51.5{ }^{\circ} \mathrm{C}, 30 \mathrm{~s} ; 72^{\circ} \mathrm{C}\right.$, $45 \mathrm{~s})$, and $1 \times\left(72^{\circ} \mathrm{C}, 10 \mathrm{~min}\right)$. PCR products were run in $1 \%$ agarose gel and the image was analyzed using Kodak Digital Science ID software. $\beta$-Actin was used as the input control. 
Immunofluorescence Staining Endothelial monolayers were fixed with methanol for $15 \mathrm{~min}$ at $-20^{\circ} \mathrm{C}$. Cell monolayers were blocked with $1 \%$ bovine serum albumin (BSA) in TBS-T (20 mm Tris, pH 7.2, and $150 \mathrm{~mm} \mathrm{NaCl)}$ and incubated with primary antibody, a mouse monoclonal antibody to human ZO-1, in PBS with $1 \%$ bovine serum albumin (Sigma) overnight at $4{ }^{\circ} \mathrm{C}$, followed by incubation with fluorescein isothiocyanate (FITC)-conjugated secondary antibodies (Pierce) at $37^{\circ} \mathrm{C}$ for $1 \mathrm{~h}$. Monolayers were rinsed three times with PBS before being sealed with 50\% glycerol-PBS. Sections were examined with an Olympus BX60 fluorescence microscope at $450 \mathrm{~nm}$.

Permeability Assay Endothelial cells were seeded (100000 cells/insert) on gelatin-coated (1\%) polystyrene filters (Costar Transwell, 0.4- $\mu \mathrm{m}$ pore size) (Corning), grown to confluence on transwell inserts, and then replaced with different media for $3 \mathrm{~h} .10 \mathrm{mg} / \mathrm{ml} \mathrm{BSA}$ in serum-free medium or $70-\mathrm{kDa}$ FITC-dextran solution $25 \mathrm{mg} / \mathrm{ml}$ in endothelial basal medium (EBM-2) (Clonetics) was added to the upper compartment. Fluid in the lower compartment was the same serum-free medium without BSA. The transfer rate across the monolayer was assessed by measuring the increase in BSA or FITC-dextran in the lower well after $30 \mathrm{~min}$. BSA was quantified with an enzyme-linked immunosorbent assay (ELISA) kit. FITC-dextran was measured with a fluorescence reader at excitation/emission of $490 / 520 \mathrm{~nm}$ and normalized to the control value.

ELISA ELISA (Alpha Diagnostic) was performed according to the manufacturer's instructions. Briefly, $100 \mu \mathrm{l}$ of diluted samples was added to each well. Plates were incubated at room temperature for $60 \mathrm{~min}$. Plates were washed five times with washing buffer and incubated with $100 \mu \mathrm{l}$ of HRP-labeled anti-bovine albumin conjugate at room temperature for $30 \mathrm{~min}$, then washed five times with washing buffer and incubated with $100 \mu \mathrm{l}$ of tetramethyl benzidine substrate solution at room temperature for $15 \mathrm{~min}$. The ELISA was stopped with $100 \mu \mathrm{l} /$ well of stop solution and read at an optical density (OD) $450 \mathrm{~nm}$.

PI3K Activity Assay The PI3K activity assay was performed as described previously. ${ }^{9)}$ Briefly, cells were lysed in $\mathrm{NaCl} 137 \mathrm{~mm}$, Tris $20 \mathrm{~mm}$, pH 7.5, $\mathrm{MgCl}_{2} 1 \mathrm{~mm}, 10 \%$ glycerol, $1 \%$ Triton $\mathrm{X}-100$, phenylmethylsulfonyl fluoride $10 \mathrm{~mm}$, and $10 \mathrm{~mm}$ each of leupeptin, aprotinin, and soybean trypsin inhibitor. Detergent lysates were immunoprecipitated with the p85-PI3K antibody (Cell Signaling) for $3 \mathrm{~h}$, and the beads were then washed twice with lysis buffer and three times with Tris- $\mathrm{HCl}$ ( $\mathrm{pH}$ 7.4). Subsequently, the precipitated immunocomplex was prepared by drying with nitrogen and resuspending in $10 \mathrm{ml}$ of $N$-(2-hydroxyethyl)piperazine- $N^{\prime}-2$ ethanesulfonic acid (HEPES) $30 \mathrm{~mm}$. This was added to wash the beads, and the tube was then left on ice for $10 \mathrm{~min}$. Kinase buffer $40 \mathrm{ml}$ (HEPES $30 \mathrm{~mm}, \mathrm{MgCl}_{2} 30 \mathrm{~mm}$, ATP $50 \mathrm{~mm}$, adenosine $200 \mathrm{~mm}$, and [g-32P]ATP $10 \mathrm{mCi}$ ) was then added to each tube. The reaction was allowed to proceed at room temperature for $15 \mathrm{~min}$ and stopped with $0.1 \mathrm{~N} \mathrm{HCl}$. The lipids were extracted with $200 \mathrm{ml}$ of chloroform/ methanol $(1: 1)$. The products were separated on potassium oxalate-pretreated TLC plates by developing with chloroform, methanol, water and 30\% ammonium hydroxide (112: $88: 19: 6$, by volume). After drying, the plates were exposed to autoradiography and the phosphorylated products quanti-

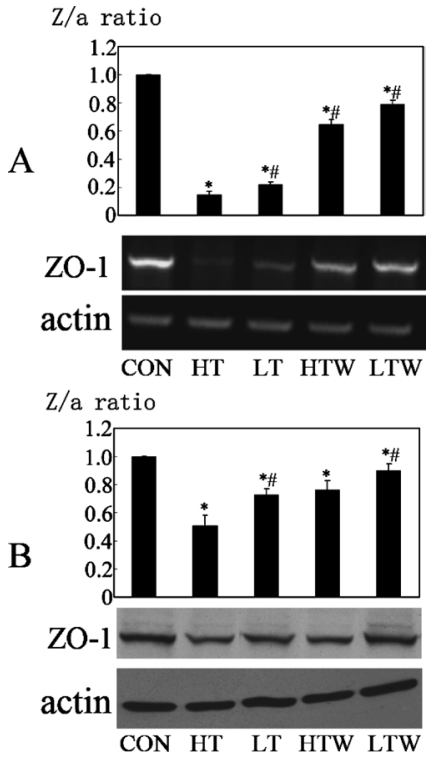

Fig. 1. Telmisartan Downregulated ZO-1 Expression in a Dose-Dependent Manner in mRNA (A) and Protein (B) Levels

The PI3K inhibitor wortmannin significantly attenuated the effects induce by telmisartan. CON, serum free medium; HT, telmisartan $1 \times 10^{-5} \mathrm{M}$; LT, telmisartan $1 \times 10^{-6} \mathrm{M}$, HTW, telmisartan $1 \times 10^{-5} \mathrm{M}$ plus wortmannin $1 \times 10^{-7} \mathrm{M}$; LTW, telmisartan $1 \times 10^{-6} \mathrm{M}$ plus wortmannin $1 \times 10^{-7} \mathrm{M}$;. The $\mathrm{Z} / \mathrm{a}$ ratio was calculated as: the ratio of $\mathrm{ZO}-1$ to actin in the control group was regarded as 1 . The $\mathrm{Z} / \mathrm{a}$ ratios in other groups were adjusted relative to the control group. * represents $p<0.05 v s$. serum-free medium control; \# represents $p<0.05 v s$. previous group.

fied by excising the spot and scintillation counting (count per minute).

Statistical Analysis All statistical calculations were performed with the SPSS 11.5 statistical software package (SPSS Inc.). Results were representative of three experiments with different cell preparations in each condition. The data are expressed as mean \pm standard deviation. Results were analyzed using one-way analysis of variance. $p$ values of less than 0.05 were considered to be statistically significant.

\section{RESULTS}

Levels of ZO-1 mRNA and Protein in TelmisartanTreated HUVECs Levels of ZO-1 mRNA expression in endothelial cells after telmisartan $\left(1 \times 10^{-5}-1 \times 10^{-6} \mathrm{M}\right)$ exposure are shown in Fig. 1A. RT-PCR revealed that telmisartan decreased the level of ZO-1 mRNA significantly. Figure $1 \mathrm{~B}$ indicates the effects of telmisartan on $\mathrm{ZO}-1$ protein expression as measured by Western blotting. Telmisartan treatment for $24 \mathrm{~h}$ significantly decreased $\mathrm{ZO}-1$ protein expression as compared with the control group. As shown in Fig. 2, valsartan $\left(1 \times 10^{-4}-1 \times 10^{-6} \mathrm{M}\right)$ had no significant effect on ZO-1 expression (mRNA or protein levels) in endothelial cells.

Subcellular Localization of ZO-1 Disrupted by Telmisartan The normal basal solute permeability level of human venous and arterial endothelial cells is governed in part by the expression and localization of the tight junctional protein ZO-1. Figure 2 shows staining of HUVEC ZO-1. Control $\mathrm{ZO}-1$ is distributed continuously around the periphery of the endothelial cells. Compared with the serum-free medium control or $1 \times 10^{-4} \mathrm{M}$ valsartan, cells exposed to telmisartan showed a loss of junctional ZO-1 localization with subsequent staining. The dose of telmisartan was positively corre- 

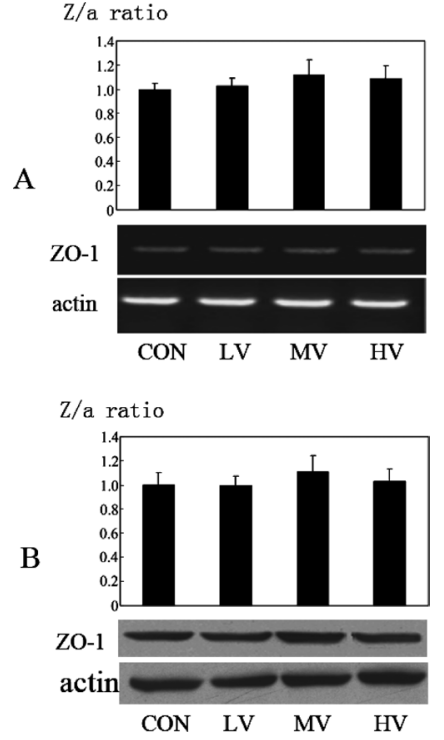

Fig. 2. Valsartan Did Not Change the Expression of ZO-1 in mRNA (A) and Protein (B) Levels at Different Concentrations

$\mathrm{CON}$, serum-free medium; $\mathrm{LV}$, valsartan $1 \times 10^{-6} \mathrm{M}$; MV, valsartan $1 \times 10^{-5} \mathrm{M}$; HV: valsartan $1 \times 10^{-4} \mathrm{M}$
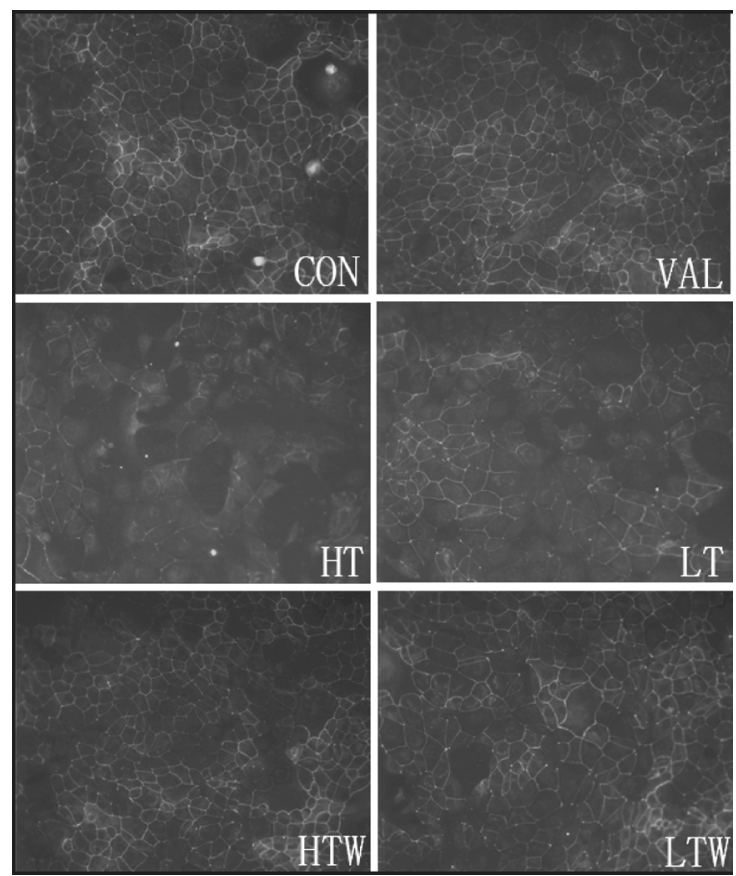

Fig. 3. Telmisartan Disrupted the Continuous Arrangement of ZO-1 along the Border of Endothelial Cells and Seemed to Be Dose-Dependent (HT, High Concentration of Telmisartan; LT, low Concentration of Telmisartan)

Valsartan $1 \times 10^{-4} \mathrm{M}(\mathrm{VAL})$ had no effect on the arrangement of ZO-1 in endothelial cells compared with the control (CON) group. The PI3K-specific inhibitor wortmannin significantly reversed the effects induced by telmisartan (LTW, low concentration of telmisartan plus wortmannin; HTW, high concentration of telmisartan plus wortman$\operatorname{nin})$

lated with the redistribution of ZO-1 (Fig. 3).

Monolayer Endothelial Permeability Increased by Telmisartan In previous experiments, we found that telmisartan decreased the expression of ZO-1 and redistributed the localization of ZO-1 in endothelial cells. To determine if telmisartan could change the permeability of endothelial cells, transwell culture was used to observe the per-

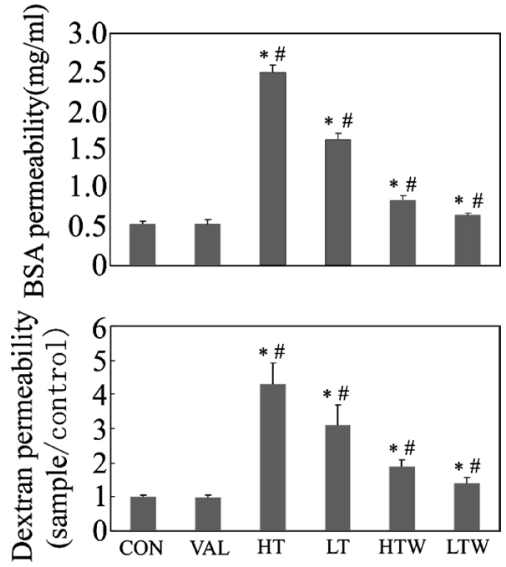

Fig. 4. Telmisartan Significantly Increased the Permeability of Endothelial Cells to BSA or Dextran

The permeability of endothelial cells increased with the concentration of telmisartan (HT, high concentration of telmisartan; LT, low concentration of telmisartan). Valsartan $1 \times 10^{-4} \mathrm{M}$ (VAL) had no effect on the permeability of endothelial cells compared with the control $(\mathrm{CON})$ group. The PI3K-specific inhibitor wortmannin attenuated the effects of telmisartan on endothelial permeability. * represents $p<0.05 v \mathrm{~s}$. serum-free medium control; \# represents $p<0.05$ vs. previous group.

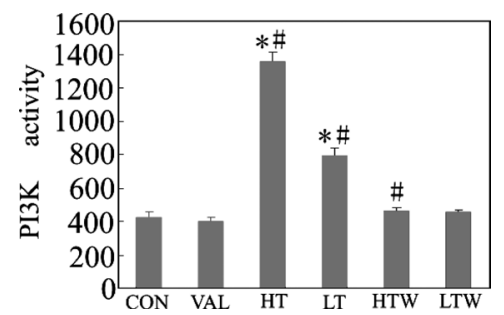

Fig. 5. The PI3K Activity Assay Confirmed That the PI3K Signaling Pathway Is Involved in the Effects Induced by Telmisartan in Our Study

Valsartan $1 \times 10^{-4} \mathrm{M}(\mathrm{VAL})$ as well as serum-free medium control (CON) had no obvious effects on PI3K activity. When endothelial cells were exposed to telmisartan (HT, high concentration of telmisartan; LT, low concentration of telmisartan), PI3K activity was significantly enhanced in a dose-dependent manner. Wortmannin (HTW, HT plus wortmannin; LTW, LT plus wortmannin) attenuated PI3K activity as well as the effects induced by telmisartan in our study. * represents $p<0.05$ vs. serum-free medium control; \# represents $p<0.05 v s$. previous group.

meability of endothelial cells to BSA and FITC-dextran. We found that telmisartan, but not valsartan, significantly increased the permeability of endothelial cells. The permeability was significantly enhanced when higher concentrations of telmisartan were used compared with lower concentrations. Valsartan $1 \times 10^{-4} \mathrm{M}$ had no effect on endothelial permeability (Fig. 4).

PI3K Signal Pathway Involvement in ZO-1 Expression and Redistribution In other studies, it was found that the PI3K signaling pathway is involved in the regulation of ZO-1 expression and localization. ${ }^{10,11)}$ In the present study, the PI3K-specific inhibitor wortmannin and PI3K activity were used, respectively, to determine the involvement of the PI3K signaling pathway in telmisartan-induced down-regulation and redistribution of ZO-1. After the addition of wortmannin $100 \mathrm{~nm}$ to cell cultures, telmisartan-induced down-regulation and redistribution of ZO-1 were significantly inhibited (Figs. $1,3,4)$. Meanwhile, the activity of PI3K was significantly increased in a dose-dependent manner when HUVECs were exposed to telmisartan. When wortmannin was added to the cell cultures, PI3K activity was attenuated significantly (Fig. 5). $1 \times 10^{-4} \mathrm{M}$ valsartan had no effect on PI3K activity (Fig. 5). 

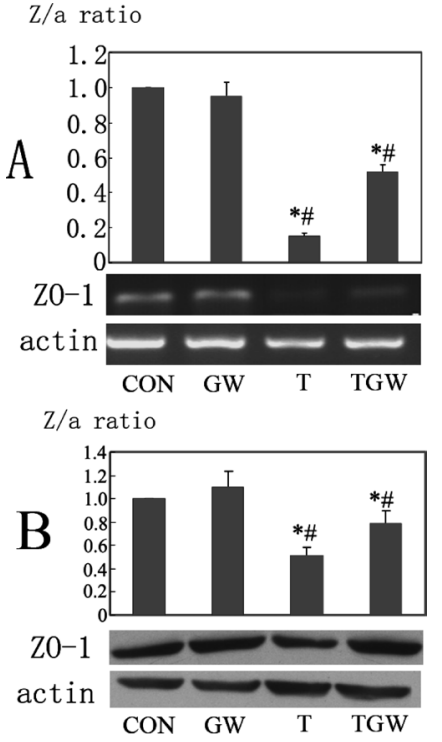

Fig. 6. Telmisartan-Induced ZO-1 Changes Were PPAR $\gamma$ Dependent

GW9662 $(5 \mu \mathrm{g} / \mathrm{ml})$ significantly enhanced ZO-1 expression, which was inhibited by telmisartan. GW9662 alone had no effect on the expression of ZO-1 in mRNA (A) and protein (B) levels. CON, serum free medium; GW, GW9662 $(5 \mu \mathrm{g} / \mathrm{ml})$; T, telmisartan $1 \times 10^{-5} \mathrm{M}$; TGW, telmisartan $1 \times 10^{-5} \mathrm{M}$ plus GW9662 $5 \mu \mathrm{g} / \mathrm{ml}$. * represents $p<0.05 v \mathrm{~s}$ serum-free medium control; \# represents $p<0.05 v s$. previous group.

Telmisartan-Induced ZO-1 Changes Were PPAR $\gamma$ Dependent Recently, some studies have demonstrated that a subset of ARBs including telmisartan have the potential to activate PPAR $\gamma$, completely independent from their angiotensin II receptor-blocking properties. ${ }^{12)}$ To illuminate the role of PPAR $\gamma$ in telmisaratan-induced ZO-1 changes, we examined the effect of GW9662, a PPAR $\gamma$ antagonist. As shown in Fig. 6, GW9662 $(5 \mu \mathrm{g} / \mathrm{ml})$ significantly blocked telmisartan-induced ZO-1 changes. GW9662 alone had no effect on the localization or expression of ZO-1.

\section{DISCUSSION}

In recent years, $A R B s$ have been used for the treatment of atherosclerosis. The permeability of endothelial cells is very important in the initiation and development of atherosclerosis. We first believed that telmisartan may enhance the barrier function between adjacent endothelial cells. However, in the present study, we found for the first time that telmisartan could alter the continuous pericellular distribution of the tight junction protein ZO-1, downregulate the expression of $\mathrm{ZO}-1$ in endothelial cells, and increase the permeability of endothelial cells. The PI3K signaling pathway was required for the action of telmisartan.

$\mathrm{ZO}-1$ is involved in signal transduction at cell-cell contacts, ${ }^{13)}$ acts as the scaffold to organize occludin at cell junction sites, ${ }^{14)}$ and links occludin to the actin cytoskeleton. ${ }^{15}$ ) Pharmacologic regulation factors such as interferon- $\gamma$, epidermal growth factor, or hepatocyte growth factor have all been shown to modulate $\mathrm{ZO}-1$ expression. ${ }^{16)}$ The expression and localization of ZO-1 can significantly influence the function of tight junctions and cell permeability. ${ }^{7,17)}$ In our study, we found that telmisartan not only downregulated the expression of ZO-1, but also altered the localization of ZO-1. In the permeability assay, we found that the barrier function of the endothelium was significantly impaired after exposure to telmisartan. These results suggest that telmisartan may increase the permeability of endothelial cells through alternation of the expression and distribution of ZO-1. The signaling pathway that regulates the expression and distribution of ZO-1 is still unclear. Fischer et al. believed that the hyperpermeability induced by $\mathrm{H}_{2} \mathrm{O}_{2}$ was caused by activation of p44/42 mitogen activated protein (MAP) kinase through changing the localization of tight junction proteins. ${ }^{18)}$ In another study of colonic epithelium, it was found that protein kinase $\mathrm{C}$, not MAPK, is involved in the regulation of ZO-1. Meanwhile, Sheth et al. found that the PI3K signaling pathway is involved in oxidative stress-induced disruption of tight junctions. ${ }^{11)}$ In the present study, we found the telmisartaninduced alternations could be significantly attenuated by the PI3K-specific inhibitor wortmannin. When PI3K activity was detected, we found that it was significantly increased when exposed to telmisartan, compared with the serum-free medium control or exposure to valsartan. These results show that the PI3K signaling pathway is at least partly involved in the $\mathrm{ZO}-1$ regulation induced by telmisartan.

It was suggested that angiotensin II played crucial roles in promoting tumor angiogenesis and cardiovascular remodeling through the induction of various growth factors, ${ }^{19)}$ which may affect the localization of tight junction proteins. ${ }^{20)}$ However, studies that reveal the relationship between angiotensin II and tight junctions are limited. In a study of diabetic nephropathy, it was found that the decrease in the intensity of ZO-1 staining and redistribution of ZO-1 from the membrane to the cytoplasm which were induced by exposure of rat glomerular epithelial cells to high glucose levels were attenuated by blockage of the angiotensin II type 1 receptor. $^{21)}$ However, there was no previous study showing that ARB can downregulate the expression and disrupt the localization of tight junctions. In our present study, no obvious effect of valsartan on ZO-1 expression and localization was found, and thus we hypothesize that angiotensin II-independent mechanisms may be involved in the regulation of $\mathrm{ZO}-1$ by telmisartan.

Recently, telmisartan has been found to bear a structural resemblance to the insulin sensitizer pioglitazone, a thiazolidinedione ligand of PPAR $\gamma .{ }^{3)}$ The ability of telmisartan to activate PPAR $\gamma$ appears to be independent of angiotensin II receptor blockade, as Schupp et al. found that these molecules could activate PPAR $\gamma$ in cells that lack angiotensin II type 1 receptors. ${ }^{22)}$ While PPAR $\gamma$ is principally expressed in adipose tissue, it can be found in a variety of cells, including endothelial cells. ${ }^{3)}$ In addition to improving insulin sensitivity, PPAR $\gamma$ activators can ameliorate multiple pathogenetic determinants of atherosclerosis. ${ }^{23,24)}$ There is a considerable body of accumulated evidence showing that PPAR $\gamma$ activators can interfere with the pathogenesis of atherosclerosis. ${ }^{25-27)}$ However the relationship between PPAR $\gamma$ and tight junctions awaits clarification. Recent studies have revealed that PPAR $\gamma$ activation can upregulate the expression of vascular endothelial growth factor (VEGF), ${ }^{4,28)}$ which plays an important role in the regulation of tight junctions. In the present study, we believed that it may be PPAR $\gamma$-dependent pathway, rather than angiotensin II-related pathway, which led to the alteration of ZO-1 expression and localization induced by telmisartan.

As a coin has two sides, so does PPAR $\gamma$. On one hand, it 
can ameliorate multiple pathogenetic determinants of atherosclerosis. On the other hand, it can increase vascular permeability and lead to side effects such as fluid retention and edema, as reported in the literature as well as in clinical registries and trials, which were partly due to VEGF. ${ }^{29)}$ VEGF itself has a dual roles in atherosclerosis. Studies demonstrating the therapeutic efficiency of VEGF suggested the opposite. ${ }^{30)}$ Based on the results, it should not be assumed that telmisartan could lead to atherosclerosis with an increase in the permeability of endothelial cells. Telmisartan may have profound biological effects in atherosclerosis, and its effects on ZO-1 in endothelial cells may be only one side of the coin. Obviously, further studies are needed to illuminate the definite relationship between telmisartan and atherosclerosis.

In conclusion, we found for the first time that telmisartan could disrupt the continuous pericellular distribution of the tight junction protein ZO-1, downregulate the expression of ZO-1 in endothelial cells, and increase the permeability of endothelial cells at least partly through PI3K signaling pathway.

Acknowledgements This work was supported by a grant from the Science and Technology Bureau of Zhejiang Province (021110240). We thank our entire laboratory for fruitful discussions.

\section{REFERENCES}

1) Johnstone M. T., Perez A. S., Nasser I., Stewart R., Vaidya A., Al Ammary F., Schmidt B., Horowitz G., Dolgoff J., Hamilton J., Quist W. C., Circulation, 110, 2060-2065 (2004).

2) Waseda K., Ozaki Y., Takashima H., Ako J., Yasukawa T., Ismail T. F., Hishida H., Ito T., Circ. J., 70, 1111-1115 (2006).

3) Benson S. C., Pershadsingh H. A., Ho C. I., Chittiboyina A., Desai P., Pravenec M., Qi N., Wang J., Avery M. A., Kurtz T. W., Hypertension, 43, 993-1002 (2004).

4) Chintalgattu V., Harris G. S., Akula S. M., Katwa L. C., Cardiovasc. Res., 74, 140-150 (2007).

5) Collins N. T., Cummins P. M., Colgan O. C., Ferguson G., Birney Y. A., Murphy R. P., Meade G., Cahill P. A., Arterioscler. Thromb. Vasc. Biol., 26, 62-68 (2006).

6) Itoh M., Furuse M., Morita K., Kubota K., Saitou M., Tsukita S., J. Cell. Biol., 147, 1351-1363 (1999).
7) Staddon J. M., Herrenknecht K., Smales C., Rubin L. L., J. Cell. Sci., 108 (Pt. 2), 609-619 (1995).

8) Bian C., Zhao K., Tong G. X., Zhu Y. L., Chen P., J. Zhejiang Univ Sci. B, 6, 631-636 (2005).

9) Bian C., Lin J., Li X. C., Wang Y. F., Hu H. Q., Chen P., Scand. J. Clin. Lab. Invest., 67, 619-631 (2007).

10) Bakin A. V., Tomlinson A. K., Bhowmick N. A., Moses H. L., Arteaga C. L., J. Biol. Chem., 275, 36803-36810 (2000).

11) Sheth P., Basuroy S., Li C., Naren A. P., Rao R. K., Biol. Chem., 278 49239-49245 (2003).

12) Clasen R., Schupp M., Foryst-Ludwig A., Sprang C., Clemenz M., Krikov M., Thone-Reineke C., Unger T., Kintscher U., Hypertension, 46, 137-143 (2005).

13) Pu H., Tian J., Andras I. E., Hayashi K., Flora G., Hennig B., Toborek M., J. Cereb. Blood Flow Metab., 25, 1325-1335 (2005).

14) Mitic L. L., Anderson J. M., Annu. Rev. Physiol., 60, 121-142 (1998).

15) Gumbiner B. M., J. Cell. Biol., 123, 1631-1633 (1993).

16) Gonzalez-Mariscal L., Betanzos A., Avila-Flores A., Semin. Cell. Dev. Biol., 11, 315-324 (2000).

17) Esser S., Lampugnani M. G., Corada M., Dejana E., Risau W., J. Cell. Sci., 111 (Pt. 13), 1853-1865 (1998).

18) Fischer S., Wiesnet M., Renz D., Schaper W., Eur. J. Cell. Biol., 84, 687-697 (2005).

19) Fujita M., Hayashi I., Yamashina S., Itoman M., Majima M., Biochem. Biophys. Res. Commun., 294, 441-447 (2002).

20) Kevil C. G., Payne D. K., Mire E., J. Biol. Chem., 273, 15099-15103 (1998).

21) Rincon-Choles H., Vasylyeva T. L., Pergola P. E., Bhandari B., Bhandari K., Zhang J. H., Wang W., Gorin Y., Barnes J. L., Abboud H. E., Diabetes, 55, 894-900 (2006).

22) Schupp M., Janke J., Clasen R., Unger T., Kintscher U., Circulation, 109, 2054-2057 (2004)

23) Che W., Lerner-Marmarosh N., Huang Q., Osawa M., Ohta S., Yoshizumi M., Glassman M., Lee J. D., Yan C., Berk B. C., Abe J., Circ. Res., 90, 1222-1230 (2002).

24) Hsueh W. A., Bruemmer D., Hypertension, 43, 297-305 (2004).

25) Corti R., Osende J. I., Fallon J. T., Wright S. D., Chaplin W. F., Badimon J. J., J. Am. Coll. Cardiol., 43, $464-473$ (2004).

26) Sidhu J. S., Cowan D., Kaski J. C., J. Am. Coll. Cardiol., 42, 17571763 (2003).

27) Sidhu J. S., Kaposzta Z., Markus H. S., Kaski J. C., Arterioscler Thromb. Vasc. Biol., 24, 930-934 (2004).

28) Kanata S., Akagi M., Nishimura S., Hayakawa S., Yoshida K., Sawamura T., Munakata H., Hamanishi C., Biochem. Biophys. Res. Commun., 348, 1003-1010 (2006).

29) Tang W. H., Maroo A., Diabetes Obes. Metab., 9, 447- 454 (2007).

30) Dulak J., Jozkowicz A., Frick M., Alber H. F., Dichtl W., Schwarzacher S. P., Pachinger O., Weidinger F., J. Am. Coll. Cardiol., 38, 2137-2138 (2001). 